\section{Efficacy and Safety of Crisaborole in \\ Patients With Mild-to-Moderate Atopic Dermatitis With and Without Comorbid Allergic Rhinitis}

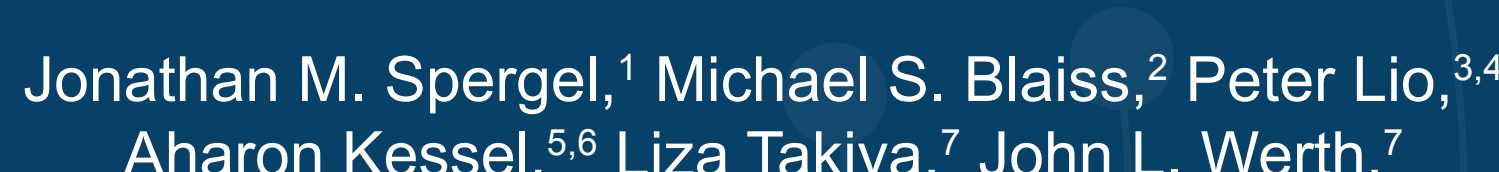
Michael A. O'Connell, ${ }^{7}$ Chuanbo Zang, 'Michael J. Cork ${ }^{8}$
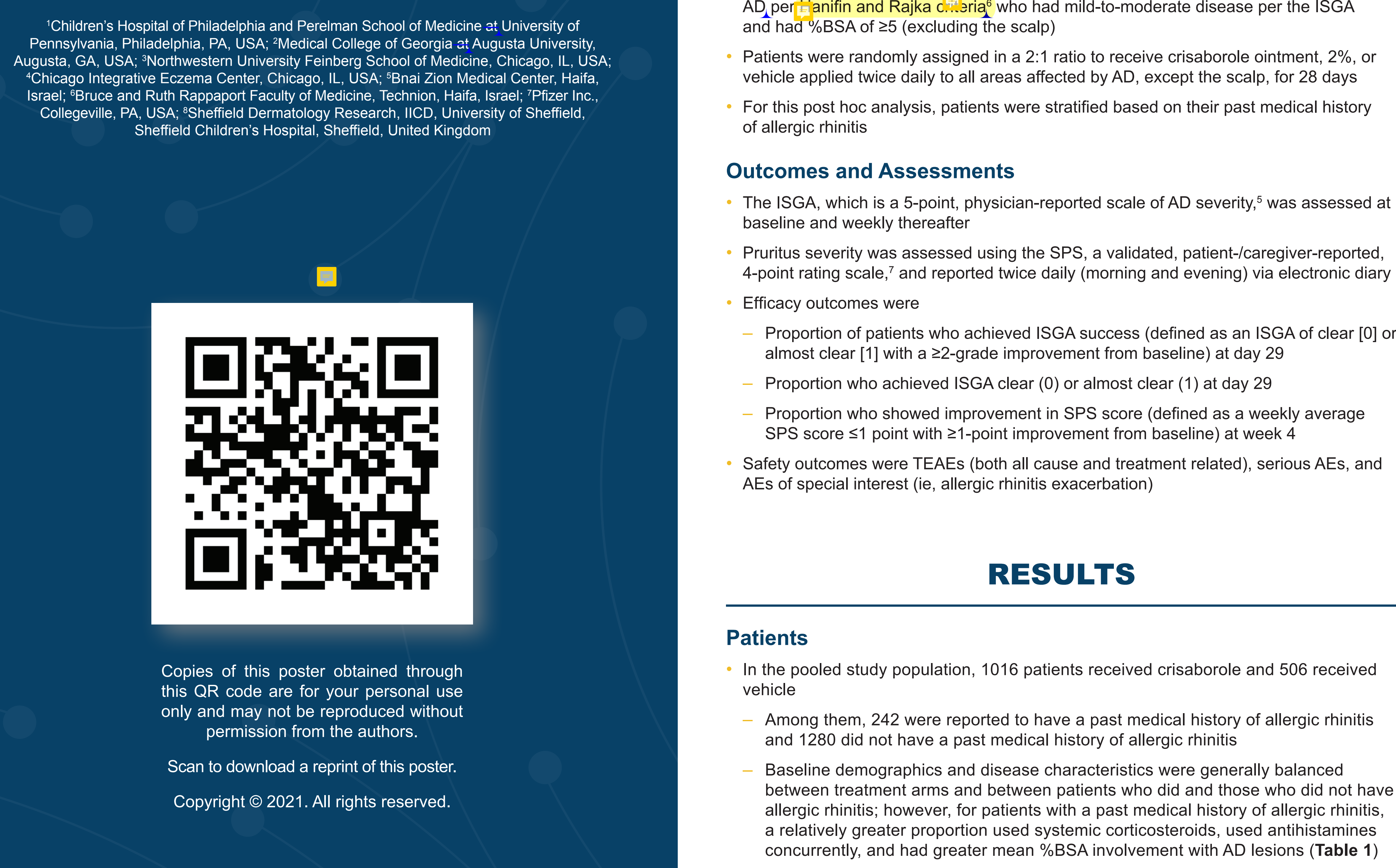

早

Acknowledgments

Editiorialmedical writing support under the guidance of the authors was provided
by Christopher M. Goodwin. PhD, at ApotheCom, San Francisco, CA. USA and was funded by Pfizer Inc, New York, NY, USA, in accordance with
Good Publication Practice (GPP) guidelines (Ann Interm Med. 2015;163:461-464)

Although it is not clear whether the presence of atopic comorbidities makes AD more

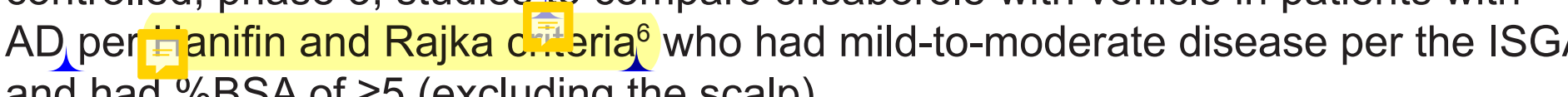

\section{INTRODUCTION}

Table 1. Baseline Demographics and Disease Characteristics topic comorbiditites, such as allergic rhinitis

Based on 1 study in the United States, the 1-year prevalence of allergic rinititis
among adults is $28 \% \%^{2}$ such as allergic rhinitis and more severe $A D$, and there is the possibility that some Crisaborole ointment, $2 \%$, is an anti-inflammatory nonsteroidal PDE 4 inhibitor for the
treatment of patients aged $\geq 3$ months $\left(22\right.$ years outside the United States) ${ }^{4}$ with mild-to-

Initial regulatory approval was based on the results from 2 identically designed,
vehicle-controleded phase 3 clinical studies: CORE 1 (NCTO2118766) and CORE 2
(NCTO2118792)

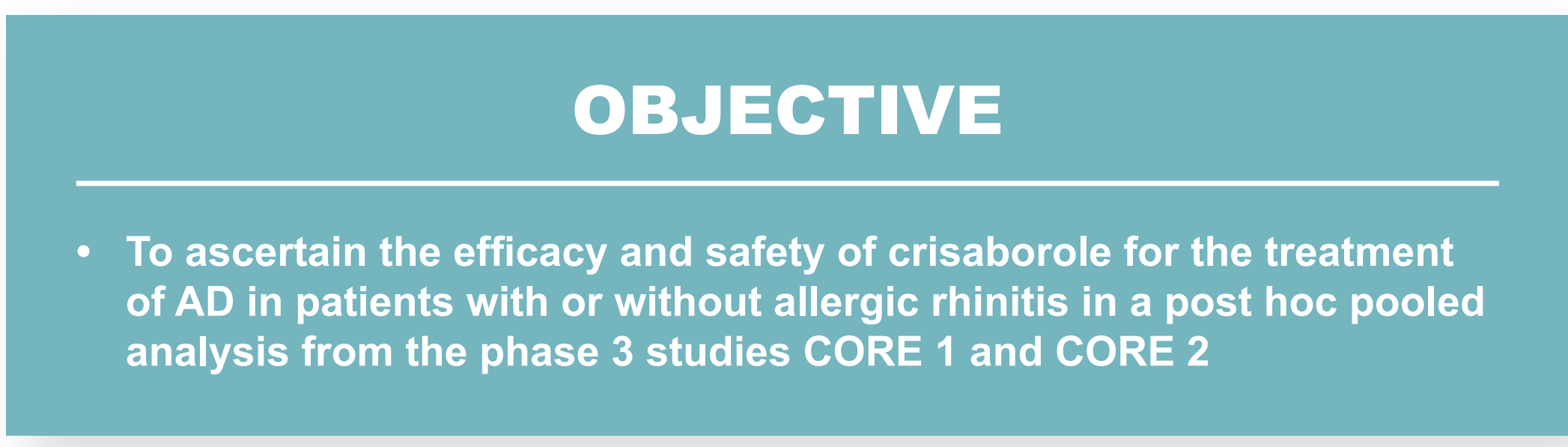

\section{METHODS}

Conter Patients were randomly assigned in a $2: 1$ ratio to receive crisaborole ointment, $2 \%$, or
vehicle applied twice daily to all areas affected by $A D$, except the scalp, for 28 days For this post hoc analysis, patients were stratified based on their past medical history
of allergic rhinitis

Outcomes and Assessments

The ISGA, which is a 5 -point, physis
baseline and weekly thereafter

Pruritus severity was assessed using the Efficacy outcomes were

Proportion of patients who achieved ISGA success (defined as an ISGA of clear [0] of Proportion who achieved ISGA clear (0) or almost clear (1) at day 29

Proportion who showed improvement in SPS score (defined as a weekly average
SPS score $\leq 1$ point with 21 -point improvement from baseline) at week 4 Safety outcomes were TEAEs (both all cause and treatmen
AEs of special interest (ie, allergic rhinitis exacerbation)

\section{RESULTS}

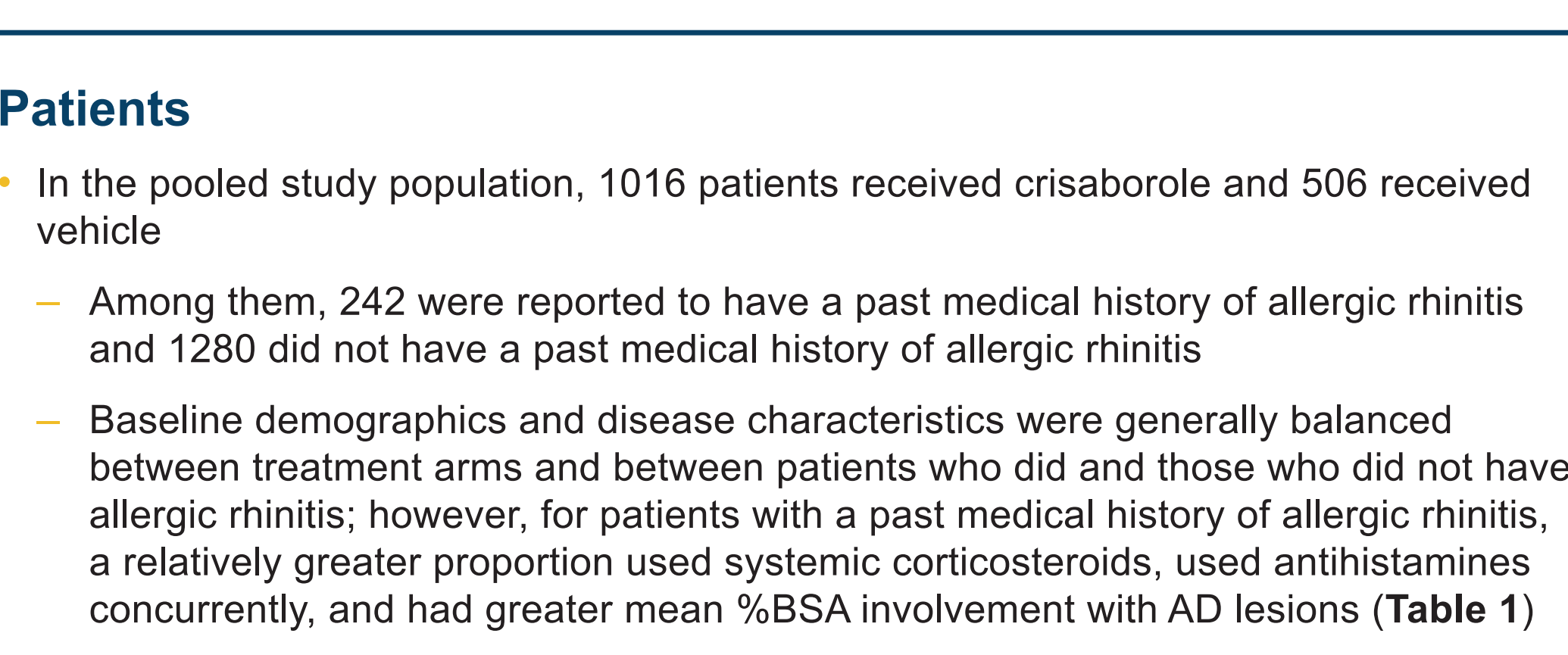

Figure 2. Proportion of Patients Who Achieved ISGA Clear or Almost Clear at Day 29
Figure 3. Proportion of Patients Who Experienced Improvement in SPS a at Week 4

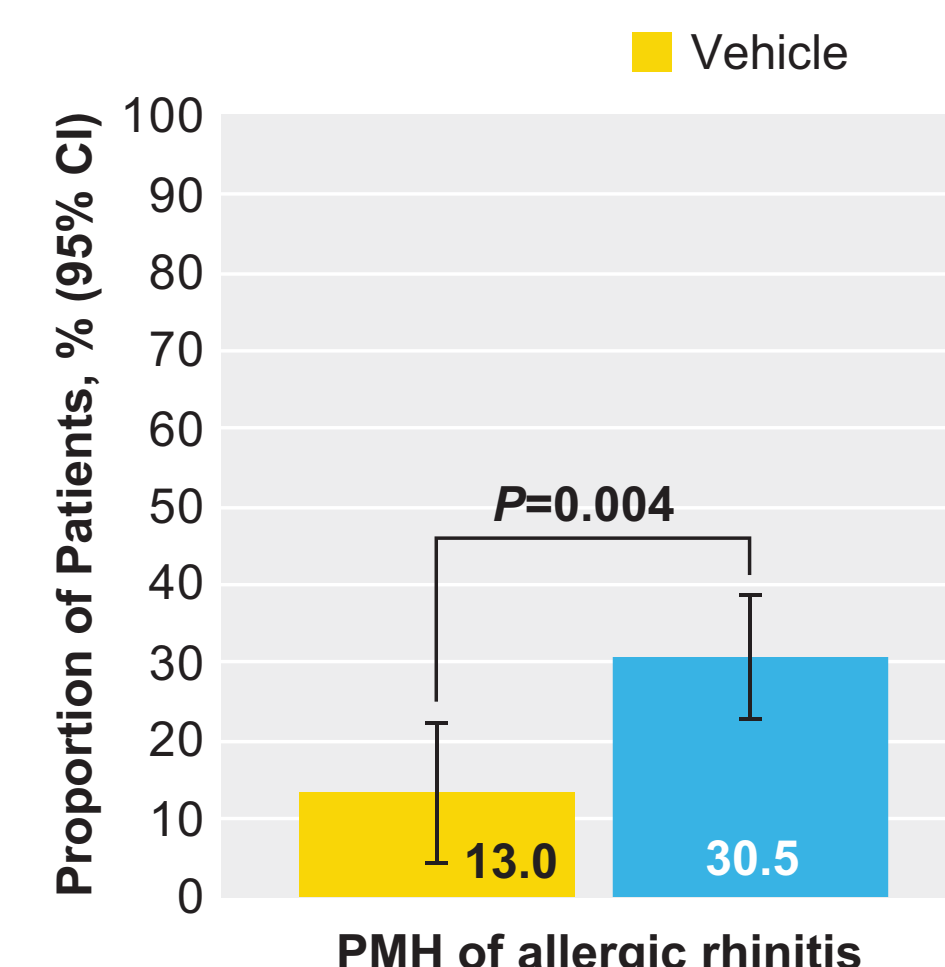
of allergic rhinitis $22.4 \quad 37.0$ PMH of allergic chinitis

\section{Safety}

The safety profile was
without allergic thinitis Among patients with alleric rinitits, 53 crisaborole-treated patients $32.5 \%$ ) and
22 venicicle-treated patients $(27.8 \%)$ experienced at least 1 all-cause TEAE Among crisaborole-treated patients with allergic rinitits, 34 patients $(20.9 \%)$
experienced a mild TTAEE, 6 patients (9.8\%) experienced a moderate TEAE, and
3 patients $(18 \%)$ experienced a severe TEAE - Individual TEAEs were infrequent (Table 2)

The most common treatment-releted TEAE in those with allergic rininitis and in those
without allergic thinititis (crisaborolole vs vehicicl) was application site pain (4.\%\% vs 1.3\%

1 crisaborole--reated patient with allergic rhinitis experienced a serious TEAE
(pneumonia, 0.6\%), and none treated with vehicle experienced a serious TEAE (0\%); he serious TEAE was not considered treatment related Allergic rhinitis was reported as an $A E$ in $\leq 2$ patients in any group; no anaphylaxis was
reported in any group

Table 2. Most Common (in >2\% patients) TEAEs (all cause) in Patients With and Patients Without Allergic Rhinitis

\begin{tabular}{|c|c|c|c|c|}
\hline & \multicolumn{2}{|c|}{ PMH of Allergic Rhinitis } & \multicolumn{2}{|c|}{ No PMH of Allergic Rhinitis } \\
\hline & $\begin{array}{c}\begin{array}{c}\text { Vehicle } \\
n=79\end{array} \\
\text { c }\end{array}$ & $\begin{array}{c}\substack{c \\
\text { Crisaborole } \\
n=163} \\
n=3\end{array}$ & $\begin{array}{c}\text { Vehicle } \\
n=420\end{array}$ & 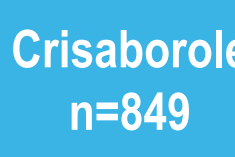 \\
\hline $\begin{array}{l}\text { AE (all cause), \% (n) } \\
\text { Application site pain }\end{array}$ & $1.3(1)$ & 4.9(8) & 1.2(5) & $4.4(37)$ \\
\hline tract infection & $3.8(3)$ & $6.1(10)$ & $3.3(14)$ & $2.8(24)$ \\
\hline $\begin{array}{l}\text { tract infection } \\
\text { tall }\end{array}$ & $3.8(3)$ & $0.6(1)$ & $1.9(8)$ & $2.9(25)$ \\
\hline Pyrexia & 2.5 (2) & 1.2(2) & $1.4(6)$ & $2.6(22)$ \\
\hline $\begin{array}{l}\text { Cough } \\
\text { Vomiting }\end{array}$ & $\begin{array}{l}0 \\
0\end{array}$ & $\begin{array}{l}0.6(1) \\
2.5(4)\end{array}$ & $\begin{array}{l}2.19) \\
1.2(5)\end{array}$ & $\begin{array}{l}1.8(15) \\
1.5(13)\end{array}$ \\
\hline $\begin{array}{l}\text { TEAEs of special } \\
\text { interesto\%(n) }\end{array}$ & & & & \\
\hline $\begin{array}{l}\text { interest, \% (n) } \\
\text { Allergic rinitis } \\
\text { Anaphylaxis }\end{array}$ & 0 & 1.2 (2) & 0.2 (1) & 0.1 (1) \\
\hline Anaphylaxis & 0 & 0 & 0 & 0 \\
\hline
\end{tabular}
The original studies
on allergic hinitits

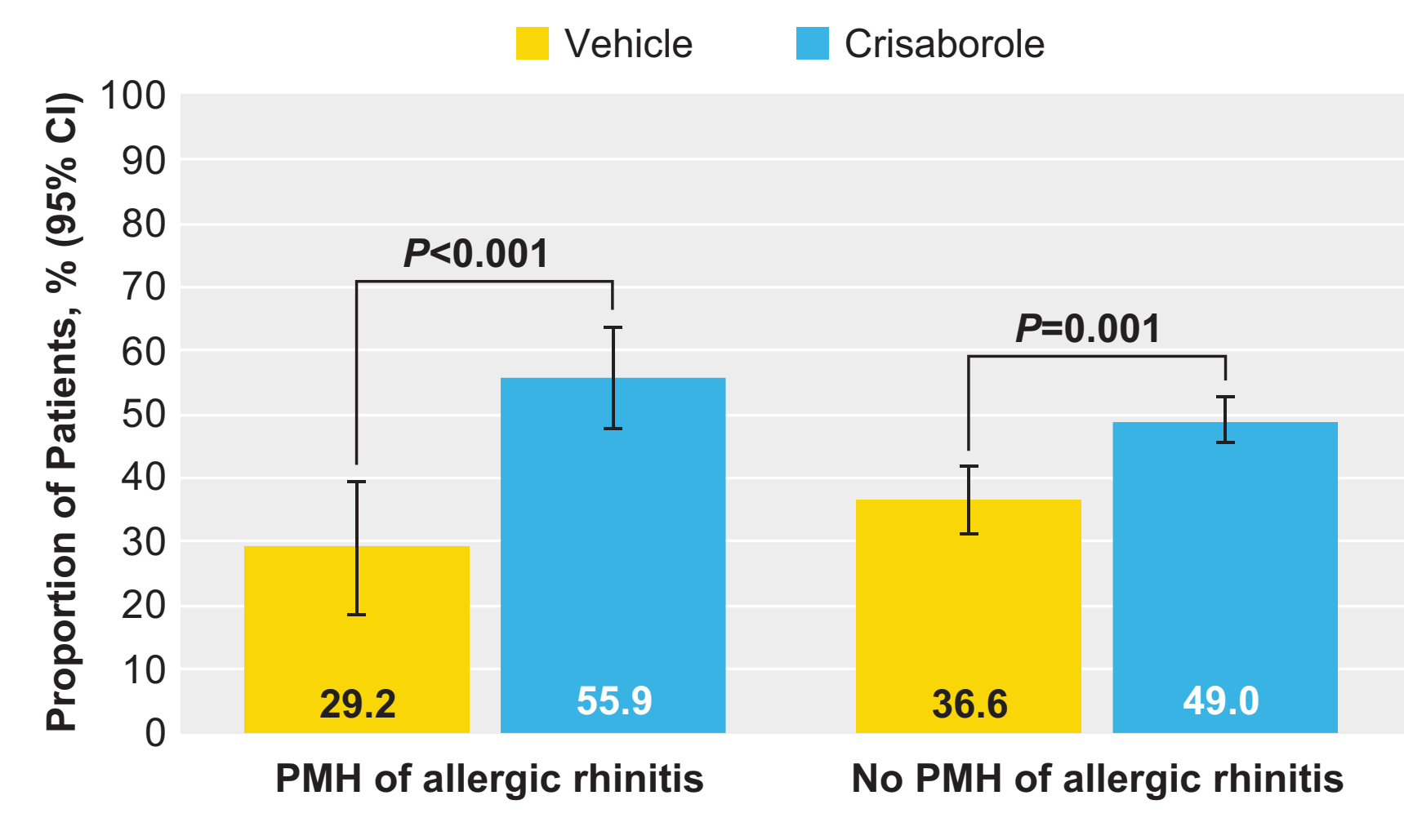

CONCLUSIONS

Regardless of whether patients have allergic rhinitits, crisaborole is
effiective in treating mild-to-moderate AD symptoms, including itch - The safety profile was generally similar between patients with signals were observec - Crisaborole should be considered for the management of $\mathrm{AD}$ in
patients whether or not the patients have concurent allergic rhin Pint of allergic rhinitis

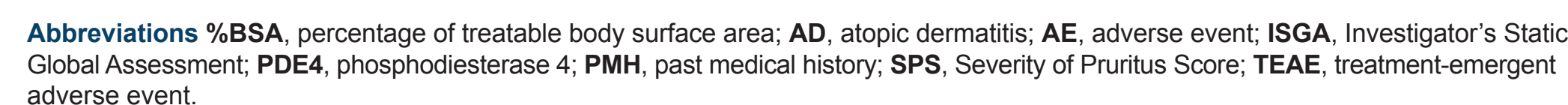

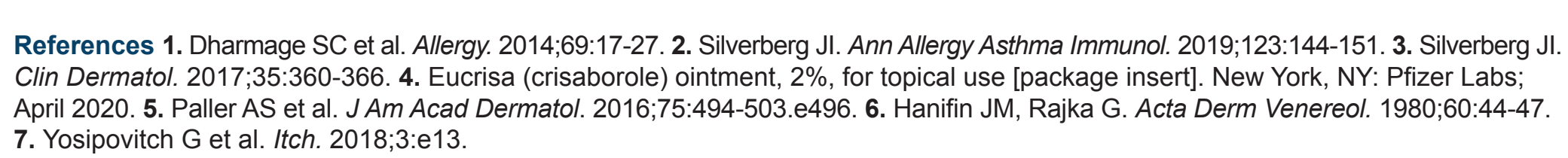

